\title{
Article \\ Curcumin Reinforces MiR-29a Expression, Reducing Mesangial Fibrosis in a Model of Diabetic Fibrotic Kidney via Modulation of CB1R Signaling
}

\author{
Yung-Chien Hsu ${ }^{1,2,+}$, Pey-Jium Chang ${ }^{1,2,3,+} \mathbb{D}$, Shih-Jiun Lin ${ }^{1}$, Chia-Ching Liaw ${ }^{4,5}\left(\mathbb{D}\right.$, Ya-Hsueh Shih ${ }^{1,2}$, \\ Lee-Wen Chen ${ }^{6, *}$ and Chun-Liang Lin $1,2,7,8,9, *$ (D)
}

check for updates

Citation: Hsu, Y.-C.; Chang, P.-J.; Lin, S.-J.; Liaw, C.-C.; Shih, Y.-H.; Chen,

L.-W.; Lin, C.-L. Curcumin Reinforces MiR-29a Expression, Reducing Mesangial Fibrosis in a Model of Diabetic Fibrotic Kidney via Modulation of CB1R Signaling. Processes 2021, 9, 694. https:// doi.org/10.3390/pr9040694

Academic Editors: Yi-Wen Liu and Ching-Hsein Chen

Received: 13 March 2021

Accepted: 9 April 2021

Published: 15 April 2021

Publisher's Note: MDPI stays neutra with regard to jurisdictional claims in published maps and institutional affiliations.

Copyright: (c) 2021 by the authors. Licensee MDPI, Basel, Switzerland. This article is an open access article distributed under the terms and conditions of the Creative Commons Attribution (CC BY) license (https:// creativecommons.org/licenses/by/ $4.0 /)$.
1 Department of Nephrology, Chang Gung Memorial Hospital, Chiayi 613016, Taiwan; libra@cgmh.org.tw (Y.-C.H.); peyjiumc@mail.cgu.edu.tw (P.-J.C.); jiun0718@gmail.com (S.-J.L.); rita1608@gmail.com (Y.-H.S.)

2 Kidney and Diabetic Complications Research Team (KDCRT), Chang Gung Memorial Hospital, Chiayi 613016, Taiwan

3 Graduate Institute of Clinical Medical Sciences, College of Medicine, Chang Gung University, Taoyuan 333423, Taiwan

4 Division of Chinese Materia Medica Development, National Research Institute of Chinese Medicine, Taipei 613016, Taiwan; liawcc@nricm.edu.tw

5 Department of Biochemical Science and Technology, National Chiayi University, Chiayi 613016, Taiwan

6 Department of Respiratory Care, Chang Gung University of Science and Technology, Chiayi 613016, Taiwan

7 School of Traditional Chinese Medicine, College of Medicine, Chang Gung University, Taoyuan 333423, Taiwan

8 Kidney Research Center, Chang Gung Memorial Hospital, Taipei 613016, Taiwan

9 Center for Shockwave Medicine and Tissue Engineering, Chang Gung Memorial Hospital, Kaohsiung 833253, Taiwan

* Correspondence: lwchen@gw.cgust.edu.tw (L.-W.C.); Linchunliang@cgmh.org.tw (C.-L.L.)

+ Yung-Chien Hsu and Pey-Jium Chang contributed equally to this work.

Abstract: Renal fibrosis is a hallmark event in the pathogenesis of diabetic nephropathy. Considerable evidence now supports that multiple intracellular signaling pathways are critically involved in renal fibrosis. Previously, our studies have shown that dysregulation of the MicroRNA 29a (miR-29a)or cannabinoid type 1 receptor (CB1R)-mediated signaling cascade in renal glomeruli substantially contributes to diabetic renal fibrosis. The purpose of the current study was to explore whether curcumin, a natural polyphenolic compound with potential renoprotective activity, could modulate the miR-29a/CB1R signaling axis to attenuate renal fibrosis. In this study, rat renal mesangial cells cultured in high glucose (HG) and the diabetic $\mathrm{db} / \mathrm{db}$ mice were used as an in vitro and in vivo model of diabetes, respectively. Our results showed that in rat renal mesangial cells, curcumin treatment substantially counteracted HG-induced changes in the expressions of miR-29a, CB1R, peroxisome proliferator-activated receptor gamma (PPAR- $\gamma$ ), and a profibrotic marker type IV collagen (collagen IV), as assessed by quantitative Real-Time Polymerase chain reaction (RT-PCR). Furthermore, in the $\mathrm{db} / \mathrm{db}$ mouse model, administration of curcumin markedly lowered urinary albumin excretion, and reduced deposition of extracellular matrices including collagen IV in renal tissues. Importantly, quantitative RT-PCR, in situ hybridization, and immunohistochemical analysis revealed that curcumin treatment consistently blocked diabetes-induced downregulation of miR29a and upregulation of CB1R in renal glomeruli. Collectively, our study provides novel evidence showing that curcumin can rescue the dysregulated miR-29a/CB1R signaling pathway in glomerular mesangium to ameliorate diabetic renal fibrosis.

Keywords: mesangial fibrosis; curcumin; microRNA-29a; cannabinoid receptor type 1 


\section{Introduction}

Diabetic nephropathy, one of the complications of diabetes mellitus, is now the leading cause of end-stage renal disease throughout the world [1]. In diabetic nephropathy, renal fibrosis is the most prominent histological feature [2]. Renal fibrosis is characterized by excessive accumulation of extracellular matrix (ECM) proteins in the glomerular mesangium and in tubulointerstitium, which causes thickening of the glomerular and tubular basement membranes, mesangial expansion, and tubulointerstitial fibrosis [3,4]. Particularly, with the progression of glomerular basement membrane thickening and mesangial expansion, glomerular capillaries are gradually occluded and the patency of capillary lumens is then decreased, which ultimately lead to renal failure [5].

It is believed that the development of renal fibrosis is a complicated biological process, which may involve numerous functionally distinct intracellular signaling pathways [6]. Several studies have implicated that the type 1 cannabinoid receptor (CB1R)-mediated signaling participates in promoting fibrosis and inflammation of renal tissue [7-11]. CB1R is a Gi/o protein-coupled receptor that has been reported to mediate various pathophysiological processes including adipogenesis [12], bone remodeling [13], neurite outgrowth [14], and liver fibrosis [15]. In our earlier studies, we also observed that CB1R expression was significantly upregulated in streptozotocin (STZ)-induced diabetic rats, and gain of CB1R function in animal models sufficiently contributed to intense renal fibrosis and inflammation [16]. Our studies further elucidated that the induction of renal fibrosis and inflammation by CB1R signaling was closely associated with decreased expression of peroxisome proliferator-activated receptor gamma (PPAR- $\gamma$ ), a nuclear hormone receptor [16]. Noteworthily, it is generally recognized that activation of PPAR- $\gamma$ signaling could exert renoprotective effects in different nondiabetic or diabetic animal models [17-20].

MicroRNAs are short non-coding RNAs that act to silence gene expression via mRNA degradation or translation repression. Notably, a large amount of evidence has shown that microRNAs are involved in various kidney diseases including diabetic nephropathy [21,22]. We previously have showed that decreased miR-29a consistently occurred in high glucose (HG)-treated mouse mesangial cells and in renal glomeruli of STZ-induced diabetic mice [23,24]. In particular, gain of miR-29a function in HG-cultured mesangial cells or in the diabetic mouse model could substantially attenuate renal fibrogenesis [24]. More recently, we found that ectopic expression of miR-29a could downregulate the detrimental CB1R signaling, consequently leading to the restoration of PPAR- $\gamma$ expression and the amelioration of renal fibrosis in STZ-treated mice [25]. Although the precise molecular mechanism underlying the action of miR-29a in renal injury is still not fully understood, miR-29a may serve as a negative regulator of CB1R signaling, and act to directly or indirectly prevent the expression of proinflammatory and profibrotic genes in renal tissues.

Curcumin, a bioactivepolyphenolic compound derived from the roots of turmeric (Curcuma longa L.), has exhibited antioxidant, anti-inflammation, anticancer, and antifibrotic activities [26,27]. Many studies exhibited that administration of curcumin could help to improve non-diabetic or diabetic renal diseases by alleviating renal inflammation and fibrosis [28]. Curcumin has been demonstrated to influence the expression or activity of several pro-inflammatory molecules such as Nuclear factor-kapa-light-chain-enhancer of activated B cells (NF- $\mathrm{KB}$ ) [29], Tumor Necrosis Factor- $\alpha$ (TNF- $\alpha$ ) [30], caveolin-1 [31], and Interleukin-1 $\beta$ (IL-1 $\beta$ ) [32]. Moreover, it has also been shown that under diabetic conditions, curcumin could retard the progression of renal fibrosis by targeting several specific signaling pathways associated with fibrogenesis [28,33]. Although curcumin has been shown to have potent antifibrotic activities, the detailed mechanism of action of curcumin in suppressing diabetic renal fibrosis has not yet been fully elucidated. Herein, we aimed to explore whether curcumin has any effects on the regulation of the miR$29 \mathrm{a} / \mathrm{CB} 1 \mathrm{R} / \mathrm{PPAR}-\gamma$ signaling axis to prevent renal fibrosis in diabetic mice. 


\section{Materials and Methods}

\subsection{Cell Culture Conditions}

Rat mesangialcells (ATCC; Manassas, VA, USA \#CRL-2573) were maintained in Dulbecco's modified eagle (DME) medium containing $10 \%$ fetal bovine serum at $37{ }^{\circ} \mathrm{C}$ with $5 \%$ Carbon dioxide. Cells cultured at $5.5 \mathrm{mM}$ D-glucose served as the normal control group. For the high-glucose culture, cells at a density of $1 \times 10^{6}$ cells per well (6-well plates) were grown in DME medium containing $35 \mathrm{mM}$ D-glucosefor $48 \mathrm{~h}$ as described previously [34]. Curcumin powder, derived from Curcuma longa,was purchased from Sigma-Aldrich (catalog \#C1386). Curcumin was dissolved in dimethyl sulfoxide (DMSO; \#D2438; Sigma-Aldrich, USA)to obtain a concentration of 10 or $50 \mathrm{mM}$, and then stored in the dark at $-20^{\circ} \mathrm{C}$. All dilutions of curcumin were made in DME medium and the final concentration of DMSO was $0.1 \%$ in all experiments of cell treatment. For cell viability analysis, mesangial cells $\left(1 \times 10^{5}\right.$ cells per well $)$ were seeded in 96-well plates and treated with normal glucose (5.5 mM D-glucose), high glucose (35 mM D-glucose), or high glucose supplemented withvarious concentrations of curcumin. After $48 \mathrm{~h}$ of treatment exposure, The Cell Proliferation Kit (XTT assay) (Roche) was used to measure cell viability according to the manufacturer's instructions.

\subsection{Quantitative Reverse-Transcription (RT)-Polymerase Chain Reaction (PCR)}

Total RNA isolation from cells (or tissues), reverse transcription of cellular RNA (Ribonucleic acid), and quantitative PCR analysis were performed as mentioned previously [35]. In brief, total RNAs extracted from cells (or tissues) were reverse-transcribed using the High-Capacity cDNA Reverse Transcription Kits (ThermoFisher Scientific, Lithuania), and the resultant complementary DNAs served as templates for quantitative PCR using the custom TaqMan ${ }^{\circledR}$ Gene Expression Assay Kits (ThermoFisher Scientific, USA) and the ABI 7300 Fast Real-Time PCR System (Applied Biosystems). The change in gene expression was calculated as $2^{-\Delta \Delta \mathrm{Ct}}$, where $\Delta \Delta \mathrm{Ct}=\Delta \mathrm{Ct}$ (treatment) $-\Delta \mathrm{Ct}$ (control) and $\Delta \mathrm{Ct}=\mathrm{Ct}($ target $)-\mathrm{Ct}(\beta$-actin $)$.

\subsection{In Vivo Animal Model}

A total of 12 6-week-old $\mathrm{db} / \mathrm{db}$ mice (C57BLKS/J Iar-+Lepr ${ }^{\mathrm{db}} /+$ Lepr $^{\mathrm{db}}$; Jackson Laboratory) were randomly divided into 2 groups. Curcumin (\#C1386; Sigma-Aldrich) was dissolved in 50\% DMSO ( $v / v$ with Phosphate Buffered Saline). Each group of the $\mathrm{db} / \mathrm{db}$ mice received intraperitoneal injections of $10 \mathrm{mg}$ curcumin $/ \mathrm{kg}$ body weight $(n=6)$ or $50 \%$ DMSO/PBS $(n=6)$ for eight weeks (five times a week). Six age-matched $\mathrm{db} / \mathrm{m}$ mice were used as the normal control group. Mice were sacrificed with an overdose of pentobarbital sodium, and then kidneys were immediately removed and weighed. The protocols of animal experiments were certified by the Institutional Animal Care and Use Committee of the Chang Gung Memorial Hospital (No. 2019091604) and were conducted following the guideline of National Institutes of Health (Bethesda, MD) and the Animal Protection Law by the Council of Agriculture (Taiwan).

\subsection{Measurement of Glycated Hemoglobulin( $\mathrm{HbA1c}$ ) Levels and Urine Albumin Excretion}

After 8-week treatment, serum levels of $\mathrm{HbA1c}$ were measured using the assay kit (Primus Diagnostics, Kansas, MO, USA) following the manufacturer's protocol. The twenty-four-hours urine samples were collected in the metabolism cages and the levels of urinary albumin were measured by the Albumin Assay Kit (Dade Behring, Newark, NJ, USA) following the manufacturer's instructions. 


\subsection{Masson's Trichrome, Periodic Acid-Schiff (PAS), and Immunohistochemicalstaining}

For assessment of collagen deposition in renal tissues, Masson's trichrome staining was performed and evaluated as described elsewhere [36]. Mesangial matrix expansion was assessed by periodic acid-Schiff staining following the manufacturer's procedures (SigmaAldrich, St Louis, MO, USA). For immunohistochemistry staining, kidneysections (5- $\mu \mathrm{m}$ thick) were immunostained with anti-collagen IV antibody (\#ab6586; Abcam, USA) or antiCB1R antibody (\#BS2712; BioWorld, USA), together with the use of the immunostaining kits (BioGenex, San Ramon, CA, USA).

\subsection{Quantitative Integrated Optical Density (IOD) Analysis}

The areas of glomeruli from each stained section were randomly chosen and photographed ( $\times 400$ magnification). The staining intensity in glomeruli was analyzed using the Image-Pro Plus software (Media Cybernetics, Silver Spring, MD, Version 6.3). For each analysis, at least 25 microscopic fields taken from a total of five sections of kidney from each mouse were quantified.

\subsection{Laser Capture Microdissection (LCM) of Kidney Tissues}

Kidneys were anatomized from mice, and then perfused with phosphate-buffered saline. Subsequently, kidney tissue slices were fixed with $4 \%$ formaldehyde, embedded in paraffin, and sectioned at 4- $\mu \mathrm{m}$ thick under RNase-free conditions. The glomerular compartments in the formaldehyde-fixed renal sections were isolated using the VeritasMicrodissectionInstrument (Arcturus Bioscience, Veritas703, CA, USA) as described previously [35]. We picked glomeruli tissue structures of any shape using a variety of drawing tools and trained the system to automatically target high-contrast labeled cells. Two hundred glomeruli from kidney sections of each mouse were collected for extraction of total RNA.

\subsection{In Situ Hybridization}

Paraffin-embedded renal sections $(5 \mu \mathrm{m})$ and the digoxigenin-labeled probe for miR-29a (Exiqon Biotechnology) were used in the insituhybridization as described previously [24]. Briefly, renal sections were first deproteinized with proteinase $\mathrm{K}(10 \mu \mathrm{g} / \mathrm{mL})$, incubated with a pre-hybridization solution (50\% formamide, $5 \mathrm{X}$ saline-sodium citrate (SSC), $0.1 \%$ Tween, $50 \mu \mathrm{g} / \mathrm{mL}$ heparin, and $500 \mu \mathrm{g} / \mathrm{mL}$ yeast RNA), and then hybridized with the digoxigenin-labeled probes in a buffer (containing $0.3 \mathrm{M}$ sodium chloride $(\mathrm{NaCl})$, $20 \mathrm{mM}$ Tris- $\mathrm{HCl}$ (hydrochloric acid), $0.5 \mathrm{mM}$ EDTA (ethylenediaminetetraacetic acid), $10 \mathrm{mM} \mathrm{NaPO} 4,10 \%$ dextran sulfate, 1 XDenhardt, and $0.5 \mathrm{mg} / \mathrm{mL}$ yeast RNA). The hybrid was subsequently detected with anti-digoxigenin antibody.

\subsection{Statistical Analysis}

All data are expressed as means \pm standard errors. For in vitro studies, data were derived from more than three independent experiments. An independent-sample t-test was utilized to evaluate the difference between the control and treatment groups. A parametric analysis of variance and Bonferroni post hoc test were used to analyze differences among different groups. $p<0.05$ was considered statistically significant.

\section{Results}

3.1. Curcumin Blocks High Glucose-Induced Changes in the Expressions of Collagen IV, CB1R, PPAR- $\gamma$, and MiR-29a in Cultured Rat Mesangial Cells

To explore the potential mechanism by which curcumin alleviates diabetic renal fibrosis, we initially evaluated the cytotoxic effects of different concentrations of curcumin on rat mesangial cells(Figure 1a). The cell viability of rat mesangial cells cultured in normal glucose (NC), high glucose (HG), or HG in combination with different concentrations $(0.1,1$, 10 , and $50 \mu \mathrm{M}$ ) of curcumin (HG + Cur) for $48 \mathrm{~h}$ were assessed by XTT assay (Figure 1a). As compared to the control HG group without curcumin, the rat mesangial cells treated with 
$0.1,1.0$, or $10 \mu \mathrm{M}$ of curcumin did not show significant changes in cell viability (Figure 1a). However, treatment with curcumin at a concentration of $50 \mu \mathrm{M}$ markedly reduced cell viability. Therefore, we used $10 \mu \mathrm{M}$ curcumin for further experiments.

Next, rat mesangial cells were cultured in the normal medium or HG medium with or without the addition of $10 \mu \mathrm{M}$ curcumin. At $48 \mathrm{~h}$ after culture, total RNAs isolated from these treated mesangial cells were used for analyzing target gene expression by quantitative RT-PCR. These specific fibrosis-related genes included collagen IV, CB1R, PPAR- $\gamma$, and miR-29a. Consistent with our previous studies [25], HG treatment significantly increased the levels of collagen IV and CB1R mRNAs (Figure 1b,c), but decreased the levels of PPAR- $\gamma$ mRNA and miR-29a RNA in mesangial cells (Figure 1d,e). In particular, curcumin treatment substantially attenuated HG-mediated upregulation of collagen IV and CB1R, and downregulation of PPAR- $\gamma$ and miR-29a in mesangial cells (Figure 1b-e). These results indicated that curcumin could suppress HG-induced mesangialfibrogenesis through modulating the miR-29a/CB1R/PPAR- $\gamma$ signaling axis.

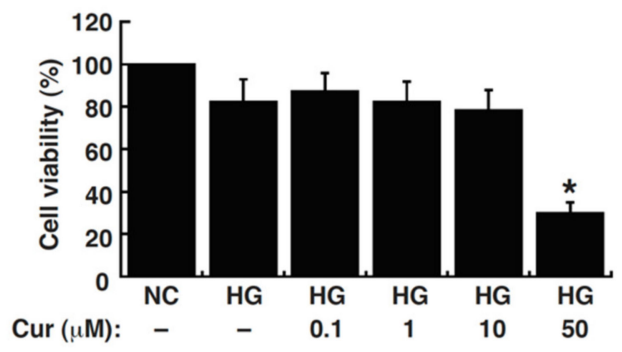

(a)

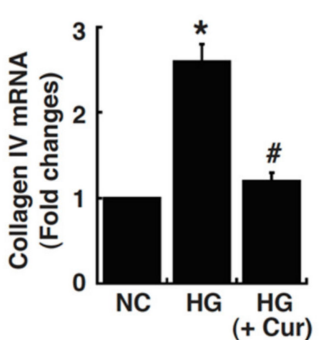

(b)

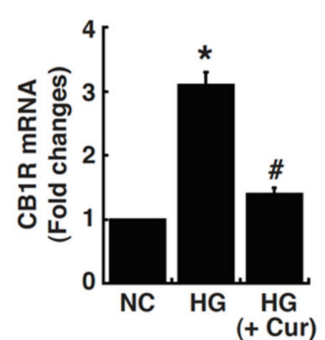

(c)

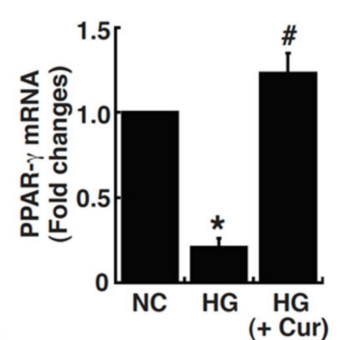

(d)

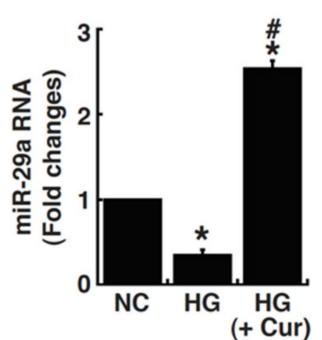

(e)

Figure 1. Effects of curcumin on cell viability and the expression of collagen IV, CB1R, PPAR- $\gamma$, and miR-29a in renal mesangial cells. (a) Rat mesangial cells were treated with normal glucose (NC), high glucose (HG), or HG supplemented with the indicated concentrations of curcumin (HG + Cur) for $48 \mathrm{~h}$. The cell viability was measured by XTT assay. Data are presented as mean \pm standard error of the mean $(\mathrm{SEM}) .{ }^{*} p<0.05$ versus HG group $(n=3)$. (b-e) Rat mesangial cells were cultured in media containing NC, HG, or HG supplemented with $10 \mu \mathrm{M}$ of curcumin (HG + Cur) for $48 \mathrm{~h}$. Expressions of collagen IV, CB1R, PPAR- $\gamma$, and miR-29a in these treated cells were evaluated by quantitative RT-PCR. Data are presented as mean \pm standard error of the mean (SEM). ${ }^{*} p<0.05$ versus NC group, $\# p<0.05$ versus HG group $(n=3)$.

\subsection{Curcumin Treatment Improves Urinary Albumin Excretion in Diabetic Mice}

To determine whether curcumin indeed improved diabetes-induced renal dysfunction in vivo, the diabetic $\mathrm{db} / \mathrm{db}$ mice were injected intraperitoneally with curcumin $(10 \mathrm{mg} / \mathrm{kg})$ five times a week and for a total of eight weeks. In comparison with the age-matched $\mathrm{db} / \mathrm{m}$ (nondiabetic) mice, the $\mathrm{db} / \mathrm{db}$ mice displayed substantially elevated levels of $\mathrm{HbA} 1 \mathrm{c}$, a common glycemic marker (Figure 2a). However, treatment of the $\mathrm{db} / \mathrm{db}$ mice with curcumin $(\mathrm{db} / \mathrm{db}+\mathrm{Cur})$ did not affect HbA1c levels (Figure 2a). Although the body and kidney weights in the $\mathrm{db} / \mathrm{db}$ mice with or without curcumin treatment were much heavier than those in the control $\mathrm{db} / \mathrm{m}$ mice, no significant difference was detected for the ratio of kidney weight to body weight among these groups (Figure 2b). Analysis of proteinuria showed that urinary albumin excretion in the $\mathrm{db} / \mathrm{db}$ mice was about 18 -fold higher than 
that in the $\mathrm{db} / \mathrm{m}$ mice (Figure $2 \mathrm{c}$ ). Elevated urinary albumin excretion in the $\mathrm{db} / \mathrm{db}$ mice could be markedly reduced by curcumin treatment (Figure 2c). These results indicated that curcumin could remarkably improve the urinary albumin excretion in $\mathrm{db} / \mathrm{db}$ mice, which was beyond blood sugar levels (HbA1c levels).

\subsection{Renal Fibrosis in Diabetic Mice Is Alleviated by Curcumin}

To look into the effect of curcumin on kidney fibrosis in diabetic mice, deposition of collagens in renal glomeruli was evaluated by Masson's trichrome staining and by immunohistochemistry (IHC) with anti-collagen IV antibody. As compared to the control $\mathrm{db} / \mathrm{m}$ mice, the $\mathrm{db} / \mathrm{db}$ mice exhibited high degrees of collagen deposition (Masson's trichrome staining) and intense collagen IV stain (IHC staining) in renal glomeruli (Figure 3a-c). The accumulation of collagens in diabetic renal glomeruli could be significantly attenuated by administration of curcumin (Figure 3a-c). To further confirm the expression levels of collagen IV in renal glomeruli, total RNAs extracted from renal glomeruli, which were isolated from kidney sections by laser capture microdissection, were subjected to real-time RT-PCR analysis. Results from the quantitative RT-PCR assay indeed showed that the mRNA levels of collagen IV were significantly reduced in the curcumin-treated $\mathrm{db} / \mathrm{db}$ mice as compared to the untreated $\mathrm{db} / \mathrm{db}$ mice (Figure $3 \mathrm{~d}$ ). Together, our results supported that curcumin treatment could attenuate renal fibrosis in the $\mathrm{db} / \mathrm{db}$ mice.

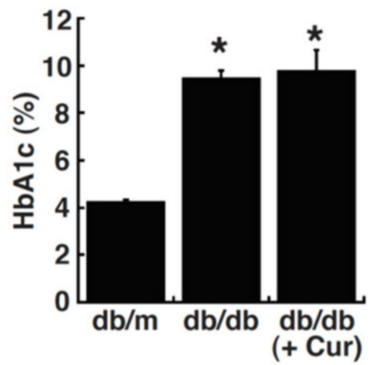

(a)

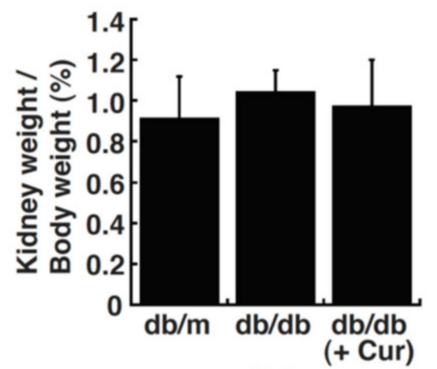

(b)

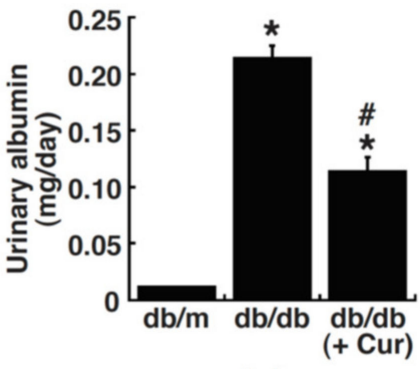

(c)

Figure 2. Curcumin reduces levels of urinary albumin excretion, but not $\mathrm{HbA1c}$ levels, in diabetic mice. Levels of $\mathrm{HbA1c}(\mathbf{a})$, the ratio of kidney weight to body weight (b), and the urinary albumin excretion (c) were measured at 8 weeks after curcumin treatment in diabetic mice. The aged-matched $\mathrm{db} / \mathrm{m}$ mice served as a control group. Data are presented as means $\pm \mathrm{SEM}$. ${ }^{*} p<0.05$ versus $\mathrm{db} / \mathrm{m}$ mice, $\# p<0.05$ versusdb/db mice $(n=6)$. 

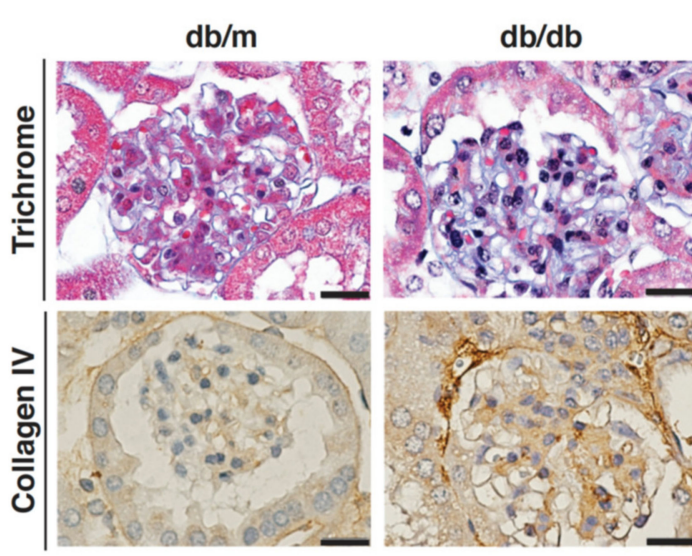

(a)

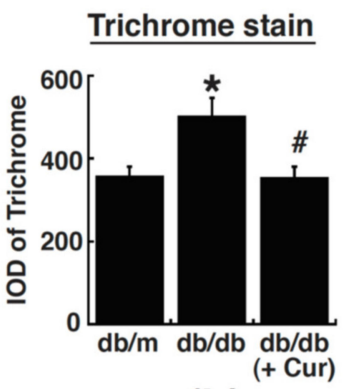

(b)

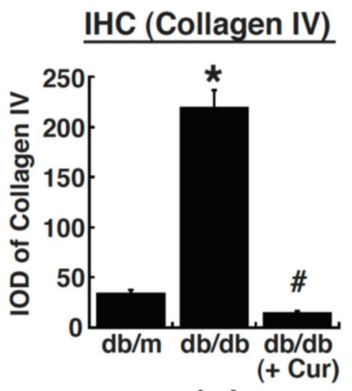

(c)

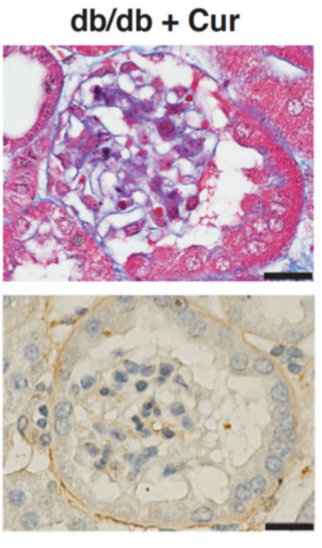

Figure 3. Curcumin attenuates deposition of collagens in renal glomeruli of diabetic mice. (a) Representative photographs of Masson's trichrome staining (Trichrome) and immunohistochemical staining of type IV collagen (collagen IV) in renal glomeruli of the $\mathrm{db} / \mathrm{m}$ mice and the $\mathrm{db} / \mathrm{db}$ mice with/without curcumin treatment. Scale bars, $20 \mu \mathrm{m}$. (b) Quantitative integrated optical density (IOD) analysis of Masson's trichrome stain of the glomerular mesangium of different treated mice. (c) Quantitative integrated optical density (IOD) analysis of the levels of collagen IV (IHC staining) in the glomerular mesangium of different treated mice. (d) Quantitative RT-PCR analysis of the collagen IV mRNA expression in the laser-capture microdissected glomeruli isolated from kidney sections of different treated mice. Data are indicated as means \pm SEM. ${ }^{*} p<0.05$ versus $\mathrm{db} / \mathrm{m}$ mice, $\# p<0.05$ versus $\mathrm{db} / \mathrm{db}$ mice $(n=6)$.

\subsection{Curcumin Treatment Suppresses CB1R Upregulation in Renal Glomeruli of Diabetic Mice}

To further examine the effect of curcumin on glomerular matrix expansion in diabetic mice, the periodic acid-Schiff (PAS) staining that delineates mesangial matrix expansion was also performed. Notably, marked mesangial matrix expansion was observed in renal glomeruli of the $\mathrm{db} / \mathrm{db}$ mice, which could be significantly attenuated by curcumin (Figure 4a,b). Since CB1R upregulation critically contributed to renal fibrosis, the expression of CB1R in renal glomeruli was also evaluated by IHC staining. Results from the IHC analysis revealed that intense CB1R stain was observed in renal glomeruli of the $\mathrm{db} / \mathrm{db}$ mice as compared to the $\mathrm{db} / \mathrm{m}$ mice (Figure $4 \mathrm{a}, \mathrm{c}$ ).Curcumin administration remarkably decreased the levels of CB1R in the $\mathrm{db} / \mathrm{dbmice}$ (Figure $4 \mathrm{a}, \mathrm{c}$ ). Additionally, the mRNA expression of CB1R in renal glomeruli isolated using the laser-capture microdissection was also analyzed by quantitative RT-PCR (Figure 4d). Consistent with the results of IHC stains, the quantitative RT-PCR analysis also demonstrated that curcumin treatment significantly reduced the glomerular CB1R expression in the $\mathrm{db} / \mathrm{dbmice}$ (Figure $4 \mathrm{~d}$ ). 

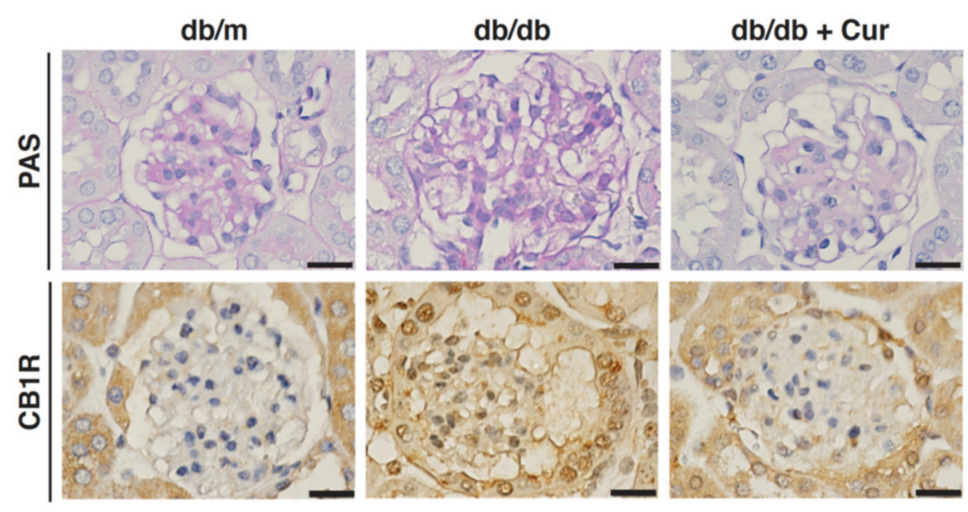

(a)

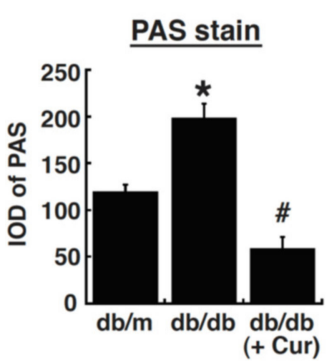

(b)

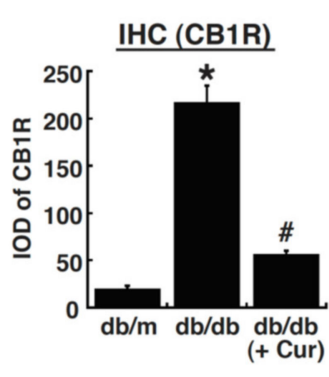

(c)

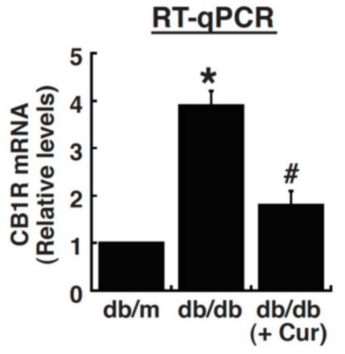

(d)

Figure 4. Curcumin suppresses diabetes-mediated CB1R upregulation. (a) Representative photographs of periodic acid-Schiff (PAS) staining and immunohistochemical staining for CB1R in renal glomeruli of the $\mathrm{db} / \mathrm{m}$ mice and the $\mathrm{db} / \mathrm{db}$ mice with or without curcumin treatment. Scale bars, $20 \mu \mathrm{m}$. (b) Evaluation of the PAS-positive matrix expansion in the glomerular mesangium by quantitative IOD analysis. (c) Evaluation of IHC staining for CB1R expression in the glomerular mesangium by quantitative IOD analysis. (d) Quantitative RT-PCR analysis of the CB1R mRNA expression in the laser-capture microdissected glomeruli isolated from kidney sections of different treatment mice. Data are presented as means \pm SEM. ${ }^{*} p<0.05$ versus $\mathrm{db} / \mathrm{m}$ mice, $\# p<0.05$ versus $\mathrm{db} / \mathrm{db}$ mice $(n=6)$.

\subsection{Curcumin Treatment Restores Mir-29a Levels in Renal Glomeruli of Diabetic Mice}

Due to the critical role of miR-29a in renal fibrosis, the expression levels of miR29 a were examined in the $\mathrm{db} / \mathrm{m}$ mice and in the $\mathrm{db} / \mathrm{db}$ mice with or without curcumin treatment. In situ hybridization confirmed that the expression levels of miR-29a were significantly lower in the $\mathrm{db} / \mathrm{db}$ mice than in the control $\mathrm{db} / \mathrm{m}$ mice (Figure $5 \mathrm{a}, \mathrm{b}$ ). However, curcumin treatment substantially restored the expression of miR-29a in glomeruli of the $\mathrm{db} / \mathrm{db}$ mice (Figure $5 \mathrm{a}, \mathrm{b}$ ). These results indicated that miR-29a might be involve in curcumin-mediated restoration of kidney function in the diabetic $\mathrm{db} / \mathrm{db}$ mice. To further confirm the expression of miR-29a in renal glomeruli, levels of miR-29a RNA were evaluated by quantitative RT-PCR. In the experiments, glomerular compartments were obtained by laser capture microdissection (Figure 5c), and total RNAs extracted from these samples were used to analyze the expression level of miR-29a RNA. As compared to the $\mathrm{db} / \mathrm{m}$ mice, the $\mathrm{db} / \mathrm{db}$ mice consistently exhibited reduced levels of the glomerular miR-29a (Figure $5 \mathrm{~d}$ ). Treatment of the $\mathrm{db} / \mathrm{db}$ mice with curcumin substantially restored the glomerular miR-29a expression (Figure $5 \mathrm{~d}$ ). 


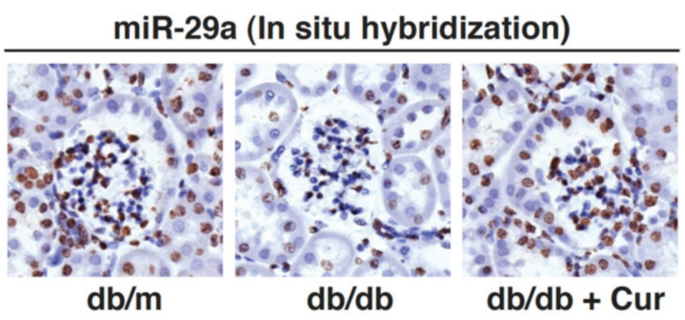

(a)

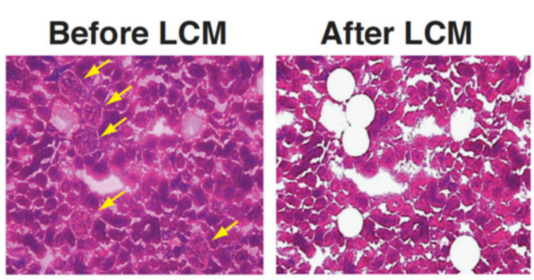

(c)

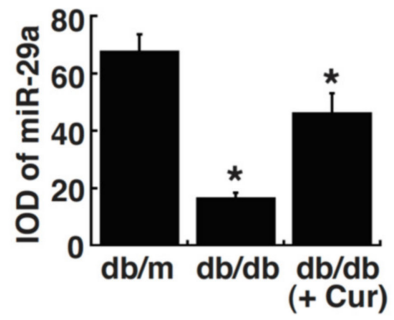

(b)

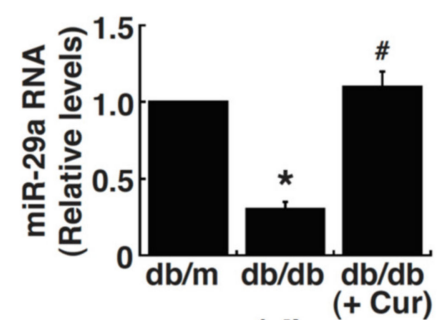

(d)

Figure 5. Effects of curcumin on miR-29a expression in diabetic glomeruli. (a) Representative in situ hybridization images of miR-29a in renal glomeruli of the $\mathrm{db} / \mathrm{m}$, untreated $\mathrm{db} / \mathrm{db}$, and curcumintreated $\mathrm{db} / \mathrm{db}$ mice. (b) Quantitative Integrated Optical Density (IOD) analysis of the levels of miR-29a shown in the insitu hybridization experiments. (c) Representative histological photographs of the renal tissue section before and after dissection of the glomerular compartments by laser capture microdissection (LCM). Yellow arrows indicate the location of glomeruli. (d) Quantitative RT-PCR analysis of the miR-29a expression in the laser-capture micro-dissected glomeruli isolated from kidney sections of the $\mathrm{db} / \mathrm{m}$, untreated $\mathrm{db} / \mathrm{db}$, and curcumin-treated $\mathrm{db} / \mathrm{db}$ mice. Data are presented as means \pm SEM. $^{*} p<0.05$ versus $\mathrm{db} / \mathrm{m}$ mice, $\# p<0.05$ versus $\mathrm{db} / \mathrm{db}$ mice $(n=6)$.

\section{Discussion}

Our earlier studies have shown that dysregulation of the miR-29a- and CB1R-mediated signaling pathways in renal glomeruli critically contributes to diabetic renal fibrosis $[16,24,25]$. In this report, we confirmed that decreased expression of miR-29a and increased expression of CB1R, along with upregulation of fibrotic markers (such as collagen IV), were consistently observed in HG-cultured renal mesangial cells and in renal glomeruli of the diabetic $\mathrm{db} / \mathrm{db}$ mice (summary in Figure 6). Importantly, we showed that curcumin treatment could efficiently rescue the dysregulated miR-29a/CB1R signaling axis to alleviate fibrogenesis in HG-cultured mesangial cells and in renal glomeruli of the $\mathrm{db} / \mathrm{db}$ mice (Figure 6). Overall, our findings suggest that targeting the miR-29a/CB1R signaling pathway in the glomerular mesangium may be a new action mechanism of curcumin to attenuate diabetic renal fibrosis.

Curcumin has attracted great attention as a potential agent for treating renal fibrosis, mainly due to its safety, cheapness, and renoprotective efficacy [28,37,38]. According to previous studies, curcumin could resolve renal fibrosis via preventing the release of proinflammatory molecules (such as Monocyte Chemoattractant Protein-1 (MCP-1), TNF- $\alpha$, and IL-1 $\beta$ ), maintaining the oxidant/antioxidant balance, inhibiting myofibroblast activation, and reducing extracellular matrix accumulation [28]. Although curcumin has been demonstrated to target several specific signaling pathways (such as transforming growth factor- $\beta$ /Smads, Extracellular Regulated protein Kinases, and Peroxisome Proliferatoractivated Receptor- $\gamma$ pathways) in various renal disease models [28], the action of curcumin in preventing glomerulosclerosis and renal fibrosis is still not yet fully understood. Due to the fact that different cell types or animal models of diabetes could potentially have differential responses to curcumin, we here tested the effect of curcumin in diabetic $\mathrm{db} / \mathrm{db}$ mice, a model of type 2 diabetic mellitus, and especially focused on the structural and functional alterations of the glomerular mesangium. Consistent with previous studies 
using the Streptozotocin (STZ)-induced diabetic animal models, we here showed that curcumin treatment remarkably prevented fibrogenesis in renal glomeruli of the $\mathrm{db} / \mathrm{db}$ mice.

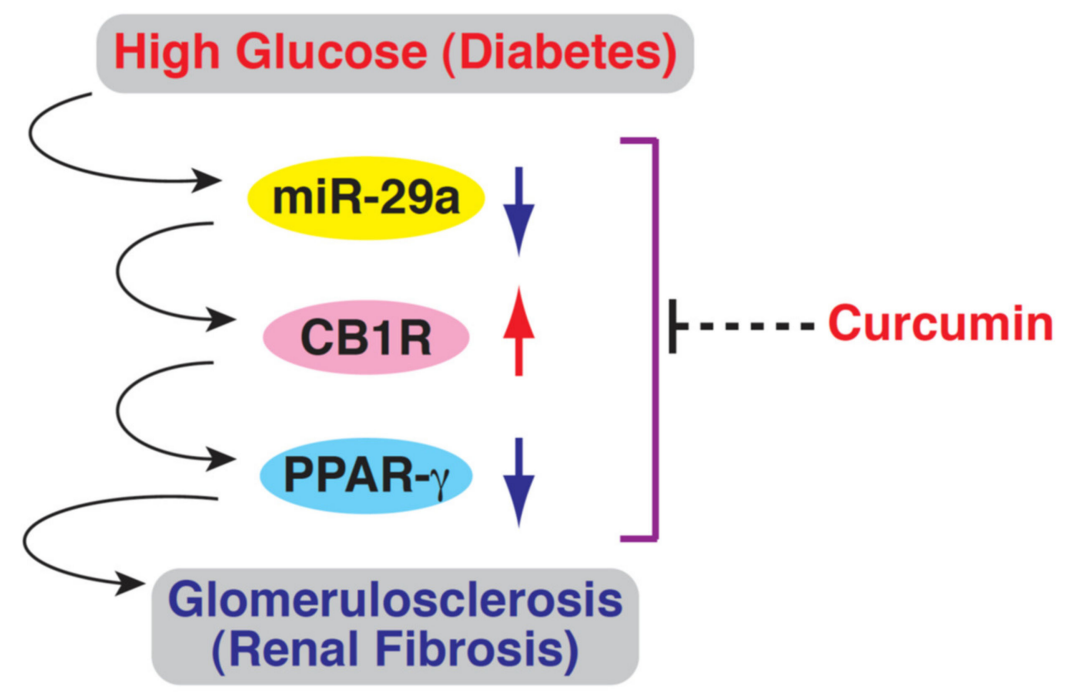

Figure 6. Schematic illustration of the dysregulated expression of miR-29a, CB1R, and PPAR- $\gamma$ in renal glomerular mesangial cells under high glucose/diabetic conditions, and the possible mechanism of action of curcumin as an anti-fibrotic agent. Under high glucose/diabetic conditions, the expression of miR-29a is decreased, which consequently triggers upregulation of CB1R, followed by downregulation of PPAR- $\gamma$ and excessive accumulation of extracellular matrices in renal glomeruli. Curcumin treatment can substantially rescue the dysregulation of the miR-29a/CB1R/PPAR- $\gamma$ signaling axis in mesangial cells to alleviate diabetic renal fibrosis.

Despite extensive studies, the current medications are still not enough to prevent the progression of diabetic nephropathy. The lack of effective treatment for diabetic nephropathy is partly due to the lack of detailed understanding of the molecular mechanisms underlying fibrogenesis. Although numerous intracellular signaling pathways and microRNAs that participate in diabetic renal fibrosis have been increasingly reported in various in vitro and animalmodels $[6,21,39]$, cross-regulation of these identified signaling cascades still remains to be further explored. Previously, we revealed that miR-29a acts as a potent antifibrotic factor in renal tissues, and the action of miR-29a in preventing diabetes-induced glomerulosclerosis could be mainly attributed to downregulation of the detrimental CB1R signaling [25]. Interestingly, we additionally found that miR-29a could positively regulate the $\mathrm{Wnt} / \beta$-catenin signaling pathway, consequently resulting in the prevention of diabetic glomerular dysfunction [24]. From the present study and previous studies, it seems likely that miR-29a plays a central role in controlling multiple fibrogenic signaling pathways. Although we have shown that curcumin could modulate the dysregulated miR-29a/CB1R/PPAR- $\gamma$ signaling pathway in diabetic $\mathrm{db} / \mathrm{db}$ mice, it may be important for future research to determine whether curcumin could affect the Wnt/ $\beta$-catenin signaling or other known downstream signaling of miR-29a to alleviate renal fibrosis in the $\mathrm{db} / \mathrm{db}$ mice.

Although miR-29a has been demonstrated as an important regulator for renal fibrosis in diabetic animals, how miR-29a expression is regulated remains poorly understood. It is possible that curcumin may function to target signaling pathways upstream of miR29a expression to alleviate diabetic renal fibrosis. Interestingly, we here noticed that the expression level of miR-29a in mesangial cells treated with HG and $10 \mu \mathrm{M}$ curcumin (Figure 1e, HG + Cur) was significantly higher than that in the normal control group (Figure 1e, NC). These results strongly imply that curcumin may be a potent inducer for miR-29a expression and may exert "dominant influence" over the effect of high glucose on the expression of miR-29a in cultured mesangial cells.Therefore, understanding the 
regulation of miR-29a expression could be an important issue to further elucidate the molecular action of curcumin in attenuating renal fibrosis. Based on the notion, crosstalk among multiple signaling pathways could be potentially required for the regulation of miR-29a expression. TGF- $\beta$ is known as a key regulator of several microRNAs in diabetic nephropathy and renal fibrosis $[22,39,40]$. It has been reported that TGF- $\beta 1$ signaling may participate in the regulation of miR-29a expression. In primary mesangial cells or podocytes, TGF- $\beta 1$ signaling could suppress the expression of miR-29 family under high glucose conditions [41]. In the established unilateral ureteral obstruction nephropathy model, TGF- $\beta$ /smad3 signaling has also been shown to negatively regulate miR-29 expression, which is critical for promoting renal fibrosis [42]. In future work, it will be interesting to know the detailed association between these complicated signaling networks, and whether curcumin treatment could modulate these signal transduction processes in some way.

Despite promising results for the use of curcumin in treating diabetic fibrosis in our studies, there are at least two issues that need to be addressed in future. First, due to the poor bioavailability of curcumin in humans, its clinical application has been greatly limited [43]. Currently, several strategies that counteract curcumin poor absorption and rapid metabolism and elimination from the body have been increasingly attempted, such as curcumin in hydrophilic nanoparticles, in the lipid-based formulation, or in a micellar system [43]. The improvement of the pharmacokinetic profile and the cellular uptake of curcumin is still challenging. On the other hand, although oral administration is the most common route for the delivery of curcumin, some studies have shown that as compared to oral administration, mice administered curcumin by intraperitoneal injection displayed higher concentrations of curcumin reached in target tissues such as brain [43-45]. Thus, intraperitoneal injection of curcumin in animals was chosen in the present study.In the future, improving bioavailability of curcuminand selectinga proper administration routewould be important for its application in treating diabetic kidney disease. Second, growing evidence has shown that the sleep circadian rhythm significantly associates withthe expression of mircoRNA including mir-29a [46]. Due to the fact that miR-29a is rhythmically expressed and involves the regulation of core clock components, mice that were intraperitoneally injected with curcumin or were sacrificed at different Zeitgeber times (ZT) or circadian times (CT) may probably lead to differential outcomes. In our study, we routinely perform animal experiments (including the intraperitoneal injection of curcumin or animal sacrifice) at a specific time period (from 10:00 a.m. to 3:00 p.m.). Therefore, to avoid animal research confounded by temporal expression of miR-29a, it may be necessary to include circadian interventions into our experimental design in the future.

\section{Conclusions}

In summary, our study presents a new mechanism of action for curcumin as an antifibrotic agent. We demonstrate that curcumin can rescue the dysregulated miR-29a/CB1R signaling pathway in renal glomeruli of diabetic mice to ameliorate renal fibrosis. These findings may be helpful in providing further insights into the complicated actions of curcumin as a renoprotective drug.

Author Contributions: Conceptualization, Y.-C.H. and C.-L.L.; methodology, Y.-C.H. and Y.-H.S.; software, Y.-H.S., L.-W.C. and S.-J.L.; validation, P.-J.C., Y.-C.H. and L.-W.C.; formal analysis, P.-J.C. and C.-C.L.; investigation, Y.-C.H. and Y.-H.S.; resources, C.-C.L.; data curation, P.-J.C., L.-W.C. and C.-L.L.; writing — original draft preparation, C.-C.L., L.-W.C. and P.-J.C.; writing-review and editing, P.-J.C. and C.-C.L.; visualization, Y.-H.S., P.-J.C. and S.-J.L.; supervision, C.-L.L.; project administration, C.-L.L.; funding acquisition, C.-L.L. All authors have read and agreed to the published version of the manuscript.

Funding: This work was supported by the medical research grants from Chang Gung Memorial Hospital at Chiayi, Taiwan (CMRPG6J0381 3).

Institutional Review Board Statement: The protocols of animal experiments were approvedby the Institutional Animal Care and Use Committee of the Chang Gung Memorial Hospital (No. 
2019091604), and were conducted following the guideline of National Institutes of Health (Bethesda, MD, USA) and the Animal Protection Law by the Council of Agriculture (Taiwan).

Informed Consent Statement: Not applicable.

Data Availability Statement: All relevant data are included within the paper.

Acknowledgments: The authors would like to thank all KDCRT members. The authors also thank the Laboratory Animal Center, Department of Medical Research, Chang Gung Memorial Hospital (Chiayi) for the technical support.

Conflicts of Interest: There is no conflict of interest.

\section{References}

1. Badal, S.S.; Danesh, F.R. New insights into molecular mechanisms of diabetic kidney disease. Am. J. Kidney Dis. 2014, 63, S63-S83. [CrossRef]

2. Murphy, M.; Docherty, N.G.; Griffin, B.; Howlin, J.; McArdle, E.; McMahon, R.; Schmid, H.; Kretzler, M.; Droguett, A.; Mezzano, S.; et al. IHG-1 amplifies TGF-beta1 signaling and is increased in renal fibrosis. J. Am. Soc. Nephrol. 2008, 19, 1672-1680. [CrossRef] [PubMed]

3. Kolset, S.O.; Reinholt, F.P.; Jenssen, T. Diabetic nephropathy and extracellular matrix. J. Histochem. Cytochem. 2012, 60, 976-986. [CrossRef]

4. Jefferson, J.A.; Shankland, S.J.; Pichler, R.H. Proteinuria in diabetic kidney disease: A mechanistic viewpoint. Kidney Int. 2008, 74, 22-36. [CrossRef]

5. Steffes, M.W.; Osterby, R.; Chavers, B.; Mauer, S.M. Mesangial expansion as a central mechanism for loss of kidney function in diabetic patients. Diabetes 1989, 38, 1077-1081. [CrossRef] [PubMed]

6. Liu, Y. Cellular and molecular mechanisms of renal fibrosis. Nat. Rev. Nephrol. 2011, 7, 684-696. [CrossRef] [PubMed]

7. Lecru, L.; Desterke, C.; Grassin-Delyle, S.; Chatziantoniou, C.; Vandermeersch, S.; Devocelle, A.; Vernochet, A.; Ivanovski, N.; Ledent, C.; Ferlicot, S.; et al. Cannabinoid receptor 1 is a major mediator of renal fibrosis. Kidney Int. 2015, 88, 72-84. [CrossRef]

8. Jourdan, T.; Szanda, G.; Rosenberg, A.Z.; Tam, J.; Earley, B.J.; Godlewski, G.; Cinar, R.; Liu, Z.; Liu, J.; Ju, C.; et al. Overactive cannabinoid 1 receptor in podocytes drives type 2 diabetic nephropathy. Proc. Natl. Acad. Sci. USA 2014, 111, E5420-E5428. [CrossRef]

9. Barutta, F.; Corbelli, A.; Mastrocola, R.; Gambino, R.; Di Marzo, V.; Pinach, S.; Rastaldi, M.P.; Perin, P.C.; Gruden, G. Cannabinoid receptor 1 blockade ameliorates albuminuria in experimental diabetic nephropathy. Diabetes 2010, 59, 1046-1054. [CrossRef]

10. Janiak, P.; Poirier, B.; Bidouard, J.P.; Cadrouvele, C.; Pierre, F.; Gouraud, L.; Barbosa, I.; Dedio, J.; Maffrand, J.P.; Le Fur, G.; et al. Blockade of cannabinoid CB1 receptors improves renal function, metabolic profile, and increased survival of obese Zucker rats. Kidney Int. 2007, 72, 1345-1357. [CrossRef]

11. Barutta, F.; Grimaldi, S.; Gambino, R.; Vemuri, K.; Makriyannis, A.; Annaratone, L.; di Marzo, V.; Bruno, G.; Gruden, G. Dual therapy targeting the endocannabinoid system prevents experimental diabetic nephropathy. Nephrol. Dial. Transplant. 2017, 32, 1655-1665. [CrossRef] [PubMed]

12. Despres, J.P.; Golay, A.; Sjostrom, L.; Rimonabant in Obesity-Lipids Study Group. Effects of rimonabant on metabolic risk factors in overweight patients with dyslipidemia. N. Engl. J. Med. 2005, 353, 2121-2134. [CrossRef] [PubMed]

13. Idris, A.I.; van't Hof, R.J.; Greig, I.R.; Ridge, S.A.; Baker, D.; Ross, R.A.; Ralston, S.H. Regulation of bone mass, bone loss and osteoclast activity by cannabinoid receptors. Nat. Med. 2005, 11, 774-779. [CrossRef]

14. Bromberg, K.D.; Ma'ayan, A.; Neves, S.R.; Iyengar, R. Design logic of a cannabinoid receptor signaling network that triggers neurite outgrowth. Science 2008, 320, 903-909. [CrossRef] [PubMed]

15. Domenicali, M.; Caraceni, P.; Giannone, F.; Pertosa, A.M.; Principe, A.; Zambruni, A.; Trevisani, F.; Croci, T.; Bernardi, M. Cannabinoid type 1 receptor antagonism delays ascites formation in rats with cirrhosis. Gastroenterology 2009, 137, 341-349. [CrossRef] [PubMed]

16. Lin, C.L.; Hsu, Y.C.; Lee, P.H.; Lei, C.C.; Wang, J.Y.; Huang, Y.T.; Wang, S.Y.; Wang, F.S. Cannabinoid receptor 1 disturbance of PPARgamma2 augments hyperglycemia induction of mesangial inflammation and fibrosis in renal glomeruli. J. Mol. Med. 2014, 92, 779-792. [CrossRef]

17. Kawai, T.; Masaki, T.; Doi, S.; Arakawa, T.; Yokoyama, Y.; Doi, T.; Kohno, N.; Yorioka, N. PPAR-gamma agonist attenuates renal interstitial fibrosis and inflammation through reduction of TGF-beta. Lab. Investig. 2009, 89, 47-58. [CrossRef]

18. Kusunoki, H.; Taniyama, Y.; Rakugi, H.; Morishita, R. Cardiac and renal protective effects of irbesartan via peroxisome proliferatoractivated receptorgamma-hepatocyte growth factor pathway independent of angiotensin II Type 1a receptor blockade in mouse model of salt-sensitive hypertension. J. Am. Heart Assoc. 2013, 2, e000103. [CrossRef]

19. Li, R.; Wang, Y.; Liu, Y.; Chen, Q.; Fu, W.; Wang, H.; Cai, H.; Peng, W.; Zhang, X. Curcumin inhibits transforming growth factor-beta1-induced EMT via PPARgamma pathway, not Smad pathway in renal tubular epithelial cells. PLoS ONE 2013, 8, e58848.

20. Zhou, X.; Zhang, J.; Xu, C.; Wang, W. Curcumin ameliorates renal fibrosis by inhibiting local fibroblast proliferation and extracellular matrix deposition. J. Pharmacol. Sci. 2014, 126, 344-350. [CrossRef] [PubMed] 
21. Mukhadi, S.; Hull, R.; Mbita, Z.; Dlamini, Z. The Role of MicroRNAs in Kidney Disease. Noncoding RNA $2015,1,192-221$. [CrossRef] [PubMed]

22. Li, R.; Chung, A.C.; Dong, Y.; Yang, W.; Zhong, X.; Lan, H.Y. The microRNA miR-433 promotes renal fibrosis by amplifying the TGF-beta/Smad3-Azin1 pathway. Kidney Int. 2013, 84, 1129-1144. [CrossRef]

23. Lin, C.L.; Lee, P.H.; Hsu, Y.C.; Lei, C.C.; Ko, J.Y.; Chuang, P.C.; Huang, Y.T.; Wang, S.Y.; Wu, S.L.; Chen, Y.S.; et al. MicroRNA-29a promotion of nephrin acetylation ameliorates hyperglycemia-induced podocyte dysfunction. J. Am. Soc. Nephrol. 2014, 25, 1698-1709. [CrossRef]

24. Hsu, Y.C.; Chang, P.J.; Ho, C.; Huang, Y.T.; Shih, Y.H.; Wang, C.J.; Lin, C.L. Protective effects of miR-29a on diabetic glomerular dysfunction by modulation of DKK1/Wnt/beta-catenin signaling. Sci. Rep. 2016, 6, 30575. [CrossRef]

25. Tung, C.W.; Ho, C.; Hsu, Y.C.; Huang, S.C.; Shih, Y.H.; Lin, C.L. MicroRNA-29a Attenuates Diabetic Glomerular Injury through Modulating Cannabinoid Receptor 1 Signaling. Molecules 2019, 24, 264. [CrossRef] [PubMed]

26. Hewlings, S.J.; Kalman, D.S. Curcumin: A Review of Its' Effects on Human Health. Foods 2017, 6, 92. [CrossRef]

27. Menon, V.P.; Sudheer, A.R. Antioxidant and anti-inflammatory properties of curcumin. Adv. Exp. Med. Biol. 2007, 595, 105-125.

28. Sun, X.; Liu, Y.; Li, C.; Wang, X.; Zhu, R.; Liu, C.; Liu, H.; Wang, L.; Ma, R.; Fu, M.; et al. Recent Advances of Curcumin in the Prevention and Treatment of Renal Fibrosis. Biomed. Res. Int. 2017, 2017, 2418671. [CrossRef]

29. Soetikno, V.; Sari, F.R.; Veeraveedu, P.T.; Thandavarayan, R.A.; Harima, M.; Sukumaran, V.; Lakshmanan, A.P.; Suzuki, K.; Kawachi, H.; Watanabe, K. Curcumin ameliorates macrophage infiltration by inhibiting NF-kappaB activation and proinflammatory cytokines in streptozotocin induced-diabetic nephropathy. Nutr. Metab. 2011, 8, 35. [CrossRef]

30. Hashem, R.M.; Soliman, H.M.; Shaapan, S.F. Turmeric-based diet can delay apoptosis without modulating NF-kappaB in unilateral ureteral obstruction in rats. J. Pharm. Pharmacol. 2008, 60, 83-89. [CrossRef]

31. Sun, L.N.; Yang, Z.Y.; Lv, S.S.; Liu, X.C.; Guan, G.J.; Liu, G. Curcumin prevents diabetic nephropathy against inflammatory response via reversing caveolin-1 Tyr14 phosphorylation influenced TLR4 activation. Int. Immunopharmacol. 2014, 23, 236-246. [CrossRef]

32. Pan, Y.; Wang, Y.; Cai, L.; Cai, Y.; Hu, J.; Yu, C.; Li, J.; Feng, Z.; Yang, S.; Li, X.; et al. Inhibition of high glucose-induced inflammatory response and macrophage infiltration by a novel curcumin derivative prevents renal injury in diabetic rats. Br. $J$. Pharmacol. 2012, 166, 1169-1182. [CrossRef]

33. Gaedeke, J.; Noble, N.A.; Border, W.A. Curcumin blocks multiple sites of the TGF-beta signaling cascade in renal cells. Kidney Int. 2004, 66, 112-120. [CrossRef]

34. Lin, C.L.; Wang, F.S.; Kuo, Y.R.; Huang, Y.T.; Huang, H.C.; Sun, Y.C.; Kuo, Y.H. Ras modulation of superoxide activates ERK-dependent fibronectin expression in diabetes-induced renal injuries. Kidney Int. 2006, 69, 1593-1600. [CrossRef]

35. Lin, C.L.; Wang, J.Y.; Ko, J.Y.; Huang, Y.T.; Kuo, Y.H.; Wang, F.S. Dickkopf-1 promotes hyperglycemia-induced accumulation of mesangial matrix and renal dysfunction. J. Am. Soc. Nephrol. 2010, 21, 124-135. [CrossRef]

36. Sugimoto, H.; Grahovac, G.; Zeisberg, M.; Kalluri, R. Renal fibrosis and glomerulosclerosis in a new mouse model of diabetic nephropathy and its regression by bone morphogenic protein-7 and advanced glycation end product inhibitors. Diabetes 2007, 56, 1825-1833. [CrossRef] [PubMed]

37. Zhang, D.W.; Fu, M.; Gao, S.H.; Liu, J.L. Curcumin and diabetes: A systematic review. Evid. Based Complement. Altern. Med. 2013, 2013, 636053. [CrossRef]

38. Prasad, S.; Aggarwal, B.B. Turmeric, the Golden Spice: From Traditional Medicine to Modern Medicine. In Herbal Medicine: Biomolecular and Clinical Aspects, 2nd ed.; Benzie, I.F.F., Wachtel-Galor, S., Eds.; CRC Press: Boca Raton, FL, USA, 2011.

39. Meng, X.M.; Tang, P.M.; Li, J.; Lan, H.Y. TGF-beta/Smad signaling in renal fibrosis. Front. Physiol. 2015, 6, 82. [CrossRef] [PubMed]

40. Wang, G.; Kwan, B.C.; Lai, F.M.; Choi, P.C.; Chow, K.M.; Li, P.K.; Szeto, C.C. Intrarenal expression of microRNAs in patients with IgA nephropathy. Lab. Investig. 2010, 90, 98-103. [CrossRef] [PubMed]

41. Wang, B.; Komers, R.; Carew, R.; Winbanks, C.E.; Xu, B.; Herman-Edelstein, M.; Koh, P.; Thomas, M.; Jandeleit-Dahm, K.; Gregorevic, P.; et al. Suppression of microRNA-29 expression by TGF-beta1 promotes collagen expression and renal fibrosis. J. Am. Soc. Nephrol. 2012, 23, 252-265. [CrossRef]

42. Qin, W.; Chung, A.C.; Huang, X.R.; Meng, X.M.; Hui, D.S.; Yu, C.M.; Sung, J.J.; Lan, H.Y. TGF-beta/Smad3 signaling promotes renal fibrosis by inhibiting miR-29. J. Am. Soc. Nephrol. 2011, 22, 1462-1474. [CrossRef]

43. Dei Cas, M.; Ghidoni, R. Dietary Curcumin: Correlation between Bioavailability and Health Potential. Nutrients 2019, 11, 2147. [CrossRef] [PubMed]

44. Schiborr, C.; Eckert, G.P.; Rimbach, G.; Frank, J. A validated method for the quantification of curcumin in plasma and brain tissue by fast narrow-bore high-performance liquid chromatography with fluorescence detection. Anal. Bioanal. Chem. 2010, 397, 1917-1925. [CrossRef] [PubMed]

45. Begum, A.N.; Jones, M.R.; Lim, G.P.; Morihara, T.; Kim, P.; Heath, D.D.; Rock, C.L.; Pruitt, M.A.; Yang, F.; Hudspeth, B.; et al. Curcumin structure-function, bioavailability, and efficacy in models of neuroinflammation and Alzheimer's disease. J. Pharmacol. Exp. Ther. 2008, 326, 196-208. [CrossRef] [PubMed]

46. Kinoshita, C.; Okamoto, Y.; Aoyama, K.; Nakaki, T. MicroRNA: A Key Player for the Interplay of Circadian Rhythm Abnormalities, Sleep Disorders and Neurodegenerative Diseases. Clocks Sleep 2020, 2, 282-307. [CrossRef] 